\section{Effects of a single-session massage for sedentary older women with prehypertension: a pilot study}

\section{Abstract}

Background: One of the consequences of population aging is the increasing prevalence of chronic diseases, including hypertension. Massage has been recognized as effective in the prevention and mitigation of the disease.

Objective: To identify the effects of a single-session massage on blood pressure and heart rate in older women with prehypertension.

Methods: The intervention consisted of one 60-minute session of Swedish massage. Fifty-eigth sedentary older women with prehypertension were treated. Blood pressure and heart rate were collected immediately before and after the intervention.

Results: Systolic blood pressure decreased 13\% $(p=0.022)$, while diastolic blood pressure decreased $9.4 \%(p=0.002)$. Heart rate decreased $17 \%(p=0.038)$.

Conclusion: A single session of Swedish massage was effective in reducing blood pressure and heart rate. Such intervention can be useful to provide safer levels of arterial blood pressure in sedentary older women with prehypertension.
Fátima Aparecida Caromano ${ }^{1}$, Felipe Monte ${ }^{1}$, Maria Helena Morgani de Almeida ${ }^{1}$, Jéssica Cândido Jerônimo da Costa ${ }^{1}$, Priscila Santos Albuquerque ${ }^{1}$, Luiz Francisco Cachoni ${ }^{1}$, Jecilene Rosana CostaFrutuoso ${ }^{2}$, Leonardo Penteado Nascimento 1 , Francis Meire Favero ${ }^{2,3}$ Luiz Carlos de Abreu ${ }^{3}$, Mariana Callil Voos 1,2

1 Faculdade de Medicina, Universidade de São Paulo (USP - SP), São Paulo (SP), Brazil.

2 Programa de pós-graduação Interdisciplinaridade em Saúde Universidade Ibirapuera, São Paulo (SP), Brazil.

3 Faculdade de Medicina do ABC.Santo André (SP), Brazil.

Contact information:

\section{Fátima Caromano}

झ caromano@usp.br

Keywords

massage, blood pressure, heart rate, aging, women 


\section{Introduction}

Population aging is a global phenomenon. It is estimated that in 2050 there will be approximately two billion people aged 60 or more, and $80 \%$ of this population will be in developing countries. By 2025, Brazil will have the sixth higher number of older adults in the world. ${ }^{1}$ Population aging may be associated with low quality of life and a higher prevalence of chronic diseases.1,2

In order to achieve better health and higher functional independence, it is necessary to minimize the number of environmental and behavioral risk factors for chronic diseases and to increase the frequency of protective factors. Physical activity, healthy diet, abstinence from smoking and alcohol, proximity to family and ergonomic environment are considered protective factors and promote healthy and functional aging. ${ }^{1,2}$

The National Health Policy for the Elderly (BRAZIL, 1999) aims to promote healthy aging, associated with the prevention of chronic diseases, such as hypertension. ${ }^{2,3}$ Hypertension is defined as a syndrome characterized by elevated blood pressure levels, associated with metabolic and hormonal changes and trophic modifications (cardiac and vascular hypertrophy). The prevalence is high and it is estimated that it is present in $15-20 \%$ of the Brazilian population, with a higher incidence among blacks and women. 3,4

Over the years, there has been a slight elevation of blood pressure in young and older adults. A study with 6.525 people aged $18-74$ years found mean values of $121 \times 78 \mathrm{mmHg}$ in people aged $18-44$ years, $135 \times 87 \mathrm{~mm} \mathrm{Hg}$ in people aged $45-$ 59 years and $148 \times 86 \mathrm{mmHg}$ in people aged 6074 years. ${ }^{5}$ Determining the normal range for older adults is important to detect the onset of the disease. The World Health Organization considers the systolic measure $140-160 \mathrm{mmHg}$ and the diastolic measure 90-95 $\mathrm{mmHg}$ as prehypertension in adults and older adults. ${ }^{1,5}$

A recent meta-analysis showed that the cardiovascular risk starts from measures $115 \times 75 \mathrm{mmHg}$ of arterial blood pressure, with a direct relationship between blood pressure levels, aging and death from vascular diseases. ${ }^{6}$ Prevention has great importance for the control of the disease. ${ }^{6}$ Among non-pharmacological measures, relaxations techniques, such as massage, have been described. ${ }^{7}$

The Swedish massage stimulates muscle metabolism and circulation. It relieves pain and induces relaxation. ${ }^{7-10}$ Kaye et al. (2008) demonstrated a that a single massage session decreased arterial blood pressure and heart rate. ${ }^{12}$ However, massage techniques habe been poorly explored as a complementary therapy for people with hypertension and prehypertension. The aim of this study was to identify the effects of a 60-minute single session of Swedish massage on blood pressure (BP) and heart rate $(H R)$ in sedentary older women with prehypertension.

\section{Methods}

This study was conducted at Laboratory of Physiotherapy and Behavior of Physiotherapy Course of the Faculty of Medicine of University of São Paulo (Brazil). The study was approved by the Ethics Committee of the Institution, process 253/13.

\section{Subjects}

This pilot study included sedentary older women with arterial blood pressure (measured after 5 minutes at rest) higher than $130 \times 80 \mathrm{mmHg}$ and lower than $160 \times 95 \mathrm{mmHg}$. Of the first 71 women sample, 13 were excluded, according to the exclu- 
sion criteria: having acute or chronic neurological, pulmonary or cardiac disease; having diabetes, cancer, dermatitis, edema or hematomas; using antihypertensive or diuretic drugs. Study participants were 58 women with mean age $64.5 \pm 1.4$ years, mean height $1.59 \pm 0.19 \mathrm{~m}$, mean weight $72.6 \pm 6.8 \mathrm{~kg}$ (mean BMI $28.7 \pm 3.9 \mathrm{~kg} / \mathrm{m}^{2}$ ). Thirteen participants were classified (according to BMI) as obese, 28 as being overweight and 18 within the normal weight range.

In order to adapt to the procedures, the participants were submitted to a Swedish massage session, a week before the intervention. They were also trained to collect $\mathrm{BP}$ and $\mathrm{HR}$ using $\mathrm{OHROM} B$ automatic device. In the following week, for five days mornings (at the same hour that the massage would be held), BP and HR were measured and recorded by the participants to establish a baseline.

The intervention consisted of the application of a 60-minute single session of Swedish massage performed in all parts of the body, except the genitals. The Swedish massage was performed by a physiotherapist with 30 years experience with massage techniques. BP and HR were collected immediately before and after the intervention. Pre and post intervention data were compared by Student's t tests.

\section{Results}

The mean baseline systolic blood pressure (SBP), considering the 5 days preceding the intervention was $131.0 \pm 3.0 \mathrm{mmHg}$. The mean systolic blood pressure (SBP) measured before the intervention was $139.1 \pm 3.5 \mathrm{mmHg}$. After the intervention, a $13.1 \%$ reduction occurred $(p=0.022)$ and the mean SBP was $124.0 \pm 4.6 \mathrm{mmHg}$.

The mean diastolic blood pressure (DBP) was $85.4 \pm 6.6 \mathrm{mmHg}$ at baseline, $89.3 \pm 7.1 \mathrm{mmHg}$ be- fore the intervention and $77.8 \pm 8.5 \mathrm{mmHg}$ after the intervention. Therefore, DBP decreased 9.4\% $(p=0.002)$ with the intervention.

Heart rate $(H R)$ was $84.5 \pm 7.3 \mathrm{bpm}$ at baseline, $85.6 \pm 9.2 \mathrm{bpm}$ before and $71.1 \pm 11.3 \mathrm{bpm}$ after the intervention. It decreased $16.8 \% \quad(p=0.038)$ with the intervention.

All participants showed a reduction in systolic and diastolic blood pressure and 32 of them had normal blood pressure levels after the massage. Also, mean BP and HR obtained on the 5-day baseline were compared with BP and HR measured before the massage session and no significant differences were found.

\section{Discussion}

In the present study, there was a decrease in systolic and diastolic BP in a group of sedentary older women with prehypertension, who underwent a single session of Swedish massage. Pre-intervention blood pressure level was compared to post intervention.

Prehypertension is a predictor of cardiovascular diseases and its treatment is primarily not pharmacological. Primary hypertension shows no clear cause, but the theory that it may be a response to chronic stress is accepted. Massage promotes relaxation ${ }^{8-12}$ and our findings show that Swedish massage can be a therapeutic option for people with prehypertension.

Cambron et al. (2006) studied different types of massage and its effects on blood pressure. They concluded that the Swedish massage has a positive effect in reducing blood pressure, while the trigger point therapy was associated with blood pressure increase. $^{13}$ The Swedish massage acts on the muscle, soft tissues, tendons, fascia and connective tis- 
sues. The repeated sensory stimulation produced by this massage induces changes in the autonomic nervous system. Thus, the blood pressure is reduced due to sympathetic activity decrease. ${ }^{13}$

A study with 50 women with prehypertension, divided into experimental and control group, showed a significant decrease in systolic and diastolic blood pressure with ten 15-minutes Swedish massage sessions applied to the face, neck, shoulders and chest. ${ }^{14}$ Another study also observed arterial blood pressure reduction after a ten session program with 10-minute sessions of Swedish massage performed in the dorsal region of individuals with hypertension. ${ }^{15}$

Conversely, Aourell et al. (2005) found evidence that contradicts theses studies. They compared the effects of Swedish massage on blood pressure, according to the massaged body surface. They found that massage applied to the back, neck and chest reduced systolic and diastolic blood pressure, whereas the massage on upper and lower limbs and face increased pressure levels. ${ }^{16}$ Although the Swedish massage is the most common type of massage technique, no previous studies had investigated the effects of this intervention when it was applied to all body surface in older women with prehypertension.

Although there are few studies about the massage intensity and its interference with arterial blood pressure, a recent study suggests that massage performed with moderate pressure (versus soft pressure) is effective mediating the benefits observed with massage therapy, modulating vagal activity. ${ }^{17}$ For massage treatment, many variables must be investigated in future studies, such as technique, duration, number of sessions, intensity, frequency, effects on body parts and populations.

This was a pilot study, restricted to sedentary older women with prehypertension, who underwent one 60-minute session of Swedish massage. It aimed to answer a specific question, however, this very specific population can also be considered a limitation of the study, which restricts generalization.

\section{Conclusion}

Our results showed that a single session of Swedish massage induced the reduction of arterial blood pressure and heart rate on sedentary older women with prehypertension. This indicates that massage may be a complementary therapy in the treatment of hypertension.

\section{References}

1. World Health Organization. Active ageing: a policy framework, 2002.

2. BRASIL. Ministério da Saúde. Portaria 1395/GM. Política de Saúde do Idoso. Brasília, DF, 1999.

3. Passos VMA, Assis TD, Barreto SM. Hypertension in Brazil: estimates from population - based prevalence studies. Epidemiol Serv Saúde. 2006;15(1):35-45

4. Carretero OA, Oparil S. Essential Hypertension, Part I: Definition and Etiology. Circulation. 2000;101:329-335.

5. Stokes GS. Management of hypertension in the elderly patient. Clin Interv Aging. 2009;4:379-389

6. Roger VL, Go AS, Lloyd-Jones DM, Benjamin EJ, Berry JD, Borden WB, et al. On behalf of the American Heart Association Statistics Committee and Stroke Statistics Subcommittee. Heart disease and stroke statistics: 2012 update, a report from the American Heart Association. Circulation, 2012; 3;125:e2-e220.

7. Field T, Quentino O, Henteleff T, Wells K.L, Delvecchio F.G, Feinberg, G. Job stress reduction therapies. Alternative Therapies.1997;3(4): 54-56.

8. Sampaio LR, Moura CV, Resende MA. Recursos Fisioterapêuticos no controle da dor Oncológica: revisão da literatura. Revista Brasileira de Cancerologia. 2005;51(4):339-346.

9. Gecsedi RA. Massage therapy for patients with cancer. Clin J Oncol Nurs. 2002;6:52-54.

10. Lawler, S.P., Cameron, L.D. Massage therapy as a technique for coping with stress. University of Auckland, New Zealand in collaboration with The New Zealand College of Massage. Poster 
presentation at the American Massage Therapy Association National Convention, Portland, OR, 2002.

11. Mary Kay Brennan, Rita D. DeBate. The effect of chair massage on stress perception of hospital bedside nurses. J Bodyw Mov Ther.2006;10, 335-342.

12. Kaye, David A, et al. The effect of deep-tissue massage therapy on blood pressure and heart rate. J Altern Complement Med. 2008;14(2):125-128.

13. Cambron JA, Dexheimer J, Coe P. Changes in blood pressure after various forms of therapeutic massage: a preliminary study. J Altern Complement Med. 2006;12(1):65-70.

14. Moeini M, Givi M, Ghasempour Z, Sadeghi M. Iran J. The effect of massage therapy on blood pressure of women with prehypertension. Nurs Midwifery Res. 2011; 16(1):61-70.

15. Olney CM. The effect of therapeutic back massage in hypertensive persons: a preliminary study. Biol Res Nurs. 2005;7(2):98-105.

16. Aourell M, Skoog M, Carleson J. Effects of Swedish massage on blood pressure. Complement Ther Clin Pract. 11.4 (2005): 242246.

17. Field T, Diego M, Hernandez-ReifM. Moderate pressure is essential for massage therapy effects. Int J Neurosci.2010;120(5):381-5.

\section{Comment on this article:}

\section{$8 B$ in $8+S P$}

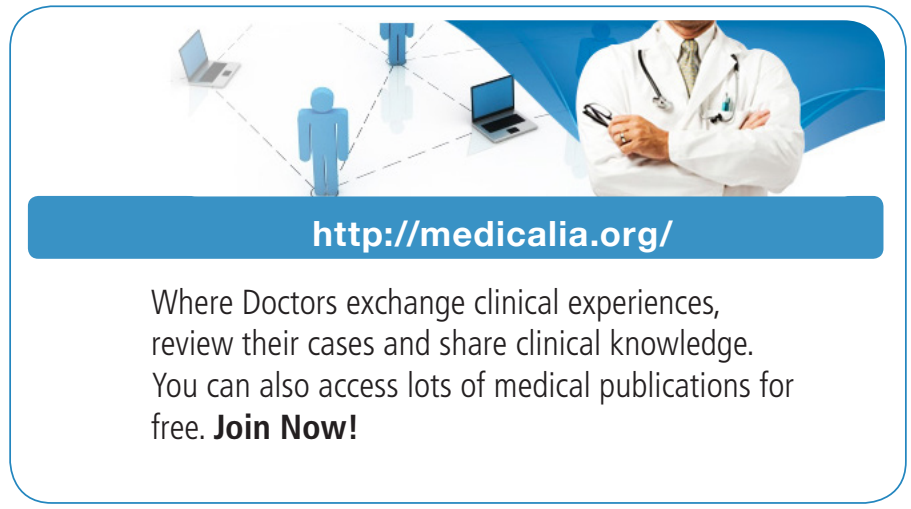

\section{Publish with iMedPub}

\section{http://www.imed.pub}

International Archives of Medicine is an open access journal publishing articles encompassing all aspects of medical science and clinical practice. IAM is considered a megajournal with independent sections on all areas of medicine. IAM is a really international journal with authors and board members from all around the world. The journal is widely indexed and classified Q1 in category Medicine. 